11

\title{
О возможности существования поверхностной электромагнитной волны в районе вечной мерзлоты
}

\author{
(C) В.К. Балханов, Ю.Б. Башкуев, В.Р. Адвокатов \\ Институт фризического материаловедения СО РАН, \\ 670047 Улан-Удэ, Россия \\ e-mail: ballar@yandex.ru
}

(Поступило в Редакцию 11 июля 2016 г. В окончательной редакции 16 февраля 2017 г.)

\begin{abstract}
Проведена интерпретация результатов измерений вертикальной компоненты электрического поля на радиотрассе с вечной мерзлотой на частоте $255 \mathrm{kHz}$. Анализ результатов измерений показал, что рассматриваемая радиотрасса обладает свойствами двухкусочной импедансной поверхности, т.е. состоит из двух участков. На расстоянии до $70 \mathrm{~km}$ от излучателя на частоте $255 \mathrm{kHz}$ электромагнитной волны уменьшение поля с расстоянием $R$ происходит степенным образом, как $R^{-1.5}$, причем степенной показатель занимает промежуточное положение между степенными показателями для уменьшения поля в свободном пространстве $R^{-2}$ и для уменьшения поля над идеально проводящей поверхностью $R^{-1}$. При дальнейшем распространении на участке от 70 до $220 \mathrm{~km}$ поле приобретает особый характер поверхностной электромагнитной волны.
\end{abstract}

DOI: 10.21883/JTF.2018.01.45491.1982

\section{1. Введение}

Для современной радиоэлектроники все еще актуальна задача создания новых радиосистем для целей дальней радиосвязи, навигации и эфирного радиовещания. В регионах Сибири и Дальнего Востока России перспективным для решения поставленной задачи является использование поверхностных электромагнитных волн (ПЭВ). Существование таких волн по аналогии с упругими поверхностными волнами Рэлея еще в 1896 г. предсказал А. Зоммерфельд [1]. ПЭВ представляют собой направленное электромагнитное излучение, локализованное вблизи поверхности раздела двух разнородных по электродинамическим характеристикам сред „воздух -диэлектрик на проводнике“ и распространяющееся вдоль этой поверхности. Из-за локализации ПЭВ затухает более медленно, чем, если бы волна распространялась вдоль идеально проводящей поверхности, и, следовательно, ПЭВ распространяется дальше, чем обычная объемная волна. ПЭВ в последнее время широко обсуждаются в теоретических исследованиях и находят свое применение в различных технических устройствах (см., например, [2-4] и списки литературы в этих работах). Распространение ПЭВ вдоль импедансной земной поверхности изучают давно, например $[5,6]$. Было установлено, что для существования электромагнитного поля в виде ПЭВ необходимо, чтобы электрическая компонента в воздухе была вертикально поляризованной. Соответственно для эффективного приема ПЭВ необходима вертикально ориентированная приемная антенна. Кроме того, подстилающая среда должна быть сильно индуктивной. Последнее означает, что фаза $\varphi$ поверхностного импеданса $\delta$ должна лежать в пределах от -45.1 до $-89.9^{\circ}$.

На земной поверхности известны три типа сильно индуктивных сред, благоприятных для осуществления дальней радиосвязи с использованием ПЭВ. Это структура „лед на соленой воде“, которая создана природой в виде Северного Ледовитого океана с его мощными паковыми льдами, и соленые озера на юге Сибири в зимневесенний период. Другая структура образуется лесной средой на почве, которой богата Россия. И третьей структурой является вечная мерзлота в Сибири и на Севере России. Последние регионы благоприятны для осуществления дальней радиосвязи с использованием ПЭВ, поскольку вечная мерзлота существует тысячелетия и мало зависит от погодных условий.

Впервые об экспериментальном обнаружении подстилающей среды с сильноиндуктивным импедансом на востоке России сообщено в монографии [7]. Затем были обнаружены ПЭВ на соленых озерах юга Бурятии [8]. Поиск других природных структур, пригодных для дальней радиосвязи, представляет важную задачу в наших исследованиях. Для выяснения вопроса о существовании ПЭВ на земной поверхности с вечной мерзлотой были проведены измерения вертикальной компоненты электрического поля на профиле длиной $220 \mathrm{~km}$ от приводной радиостанции с излучаемой мощностью $P=1 \mathrm{~kW}$ на частоте $255 \mathrm{kHz}$. Измерения проводились на прямой радиотрассе вблизи федеральной автомобильной дороги A360 между населенными пунктами Чульман (56 50' N.B. $124^{\circ} 54^{\prime}$ E.L.) и Алдан $\left(58^{\circ} 36^{\prime}\right.$ N.B. $125^{\circ} 24^{\prime}$ E.L.) [9]. Рассматриваемый район характеризуется наличием вечной мерзлоты толщиной до $200 \mathrm{~m}$, лежащей на древнем Алданском щите с удельным электрическим сопротивлением порядка до $1-5 \mathrm{k} \Omega \cdot \mathrm{m}[10]$. На рис. 1 ромбиками представлены результаты измерений зависимости уровня вертикальной компоненты переменного электрического поля от расстояния до излучателя. Появление сплошной линии на рисунке будет разъяснено ниже. Анализ результатов измерений показывает, что их нельзя представить в виде единой для всей радиотрассы 
степенной функции, а также любой другой более или менее простой аналитической формулы. Задачу определения зависимости электрического поля от расстояния можно решить, если для каждого участка радиотрассы устанавливать свою определенную функциональную зависимость.

\section{Участок ПЭв}

Измерение переменного электрического поля проводилось вертикальной электрической антенной с селективным микровольтметром FSM-6, чувствительностью не ниже $1 \mathrm{mkV} / \mathrm{m}$. Первое измерение проводилось возле населенного пункта Алдан, на расстоянии примерно $220 \mathrm{~km}$ от аэропорта в населенном пункте Чульман, где находилась приводная радиостанция. На рис. 1 первое измерение представлено ромбиком, расположенным в нижнем правом углу. Остальные измерения проводились, последовательно приближаясь к приводной радиостанции. На рис. 1 результаты измерений представлены в виде ромбиков, приближающихся к верхнему левому углу.

По результатам первых 16 измерений установлено, что уровни вертикальной компоненты электрического поля $E(R)$ в зависимости от расстояния $R$ от излучателя удовлетворительно описываются формулой

$$
E(R)=A R^{-0.5} \exp (-B R) .
$$

Здесь $A=3.5, B=0.013$ с погрешностью менее $\pm 5 \%$, метод вычисления этих чисел изложен в $[11,12]$. Поле $E(R)$ измерено в $\mathrm{mV} / \mathrm{m}$, а расстояние $R$ в $\mathrm{km}$.

На рис. 2 в виде ромбиков представлены измеренные значения уровней поля и сплошная линия, построенная по формуле (1). Рассматриваемый первый участок назовем участком ПЭВ. Такое название связано с тем, что зависимость (1) описывает ПЭВ. Если среда характеризуется поверхностным импедансом $\delta$, а излучаемая

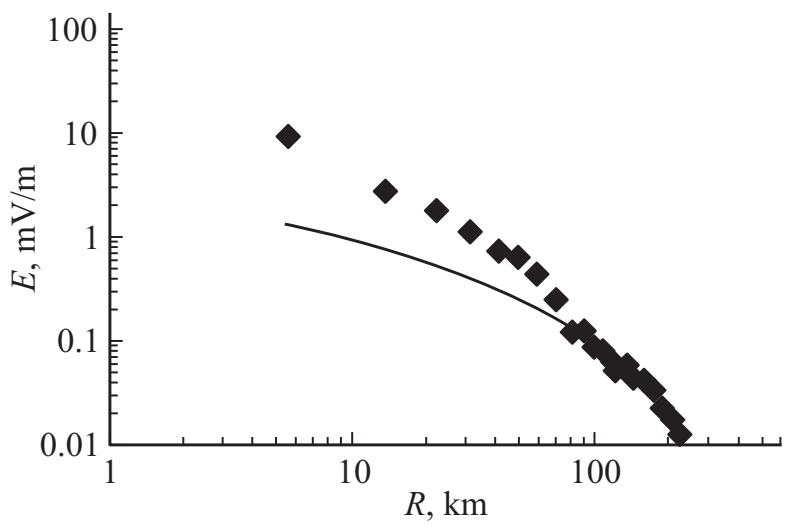

Рис. 1. Результаты измерений на радиотрассе от 5 до $220 \mathrm{~km}$ в билогарифмическом масштабе. Ромбики - значения уровней вертикальной компоненты электрического поля в пунктах измерений. Сплошная кривая - уровни ПЭВ (пояснение в тексте).

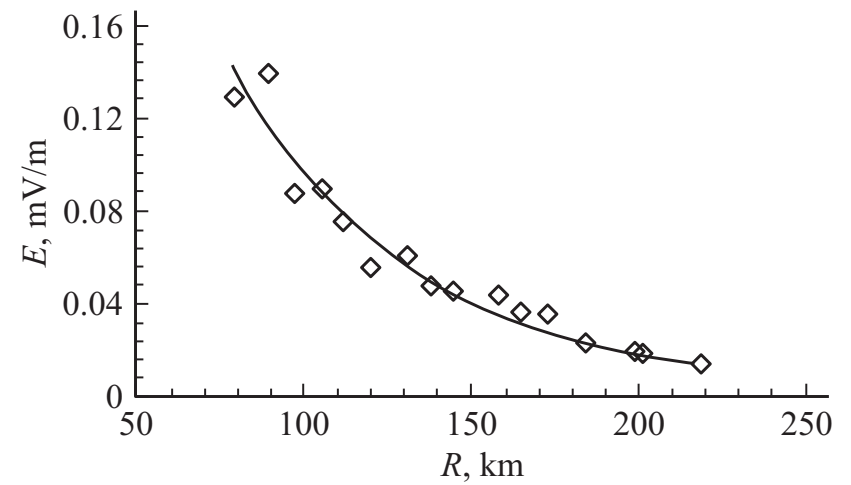

Рис. 2. Участок ПЭВ. Ромбики - измеренные значения, сплошная линия - вычисленная по формуле (1).

мощность $P$, то вертикальная компонента электрического поля на поверхности земли на расстоянии $R$ от излучателя будет [13-15]

$$
\begin{aligned}
E(R)= & \left|E_{z}(\mathrm{mV} / \mathrm{m})\right|=300 \sqrt{P(\mathrm{~kW})} \frac{2 \pi|\delta|}{\sqrt{\alpha \lambda(\mathrm{km}) R(\mathrm{~km})}} \\
& \times \exp \left(-\frac{2 \pi}{\lambda(\mathrm{km})} \operatorname{Re} \delta|\operatorname{Im} \delta| R(\mathrm{~km})\right)
\end{aligned}
$$

Здесь $\lambda$ - длина волны, для рассматриваемой приводной радиостанции $\lambda=1.176 \mathrm{~km} ; \operatorname{Re} \delta$ и $\operatorname{Im} \delta$ - действительная и мнимая части поверхностного импеданса $\delta$. Традиционный множитель 300 является размерным множителем, составленным из диэлектрической и магнитной постоянных вакуума и коэффициентом усиления антенны. Множитель $\alpha=2 \cdot 10^{3}$ в квадратном корне появился из того, что электрическое поле $E$ измеряется в $\mathrm{mV} / \mathrm{m}$, мощность $P$ в $\mathrm{kW}$, а длины $\lambda$ и $R$ в $\mathrm{km}$.

Сравнивая (1) и (2), сначала находим

$$
|\delta|=\frac{A \sqrt{\lambda(\mathrm{km})}}{42.17} .
$$

Откуда, подставляя $\lambda=1.176 \mathrm{~km}$ и $A=3.5$, находим $|\delta|=0.09$. Далее, поскольку импеданс $\delta=|\delta| \exp (i \varphi)$, то фазу импеданса можно находить из следующего выражения:

$$
\sin (-2 \varphi)=\frac{\lambda B}{\pi|\delta|^{2}}
$$

Подставляя $B=0.013$, находим $\varphi=-71.5^{\circ}$. Причем из двух решений уравнения (4) выбиралось то, которое ближе к $-90^{\circ}$. Теперь можно найти импеданс рассматриваемой радиотрассы

$$
\delta=0.028-i 0.085 \text {. }
$$

\section{Второй участок}

Совпадение на рис. 2 измеренных значений уровня поля с вычисленными по формуле (1) показывает, что 


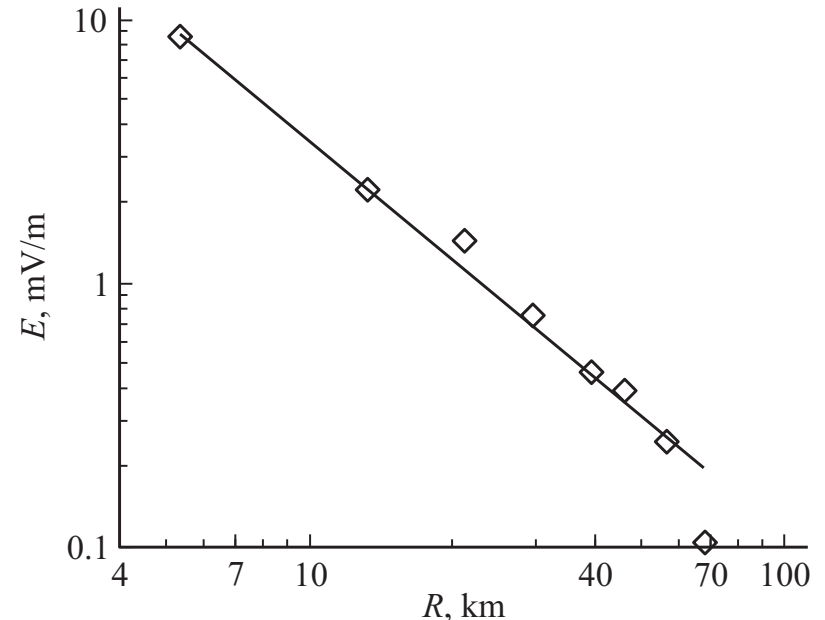

Рис. 3. Вертикальная компонента электрического поля на участке от 5 до $70 \mathrm{~km}$ от излучателя в билогарифмическом масштабе. Ромбики - измеренные значения, сплошная линия вычисленная по формуле (6).

участок от 70 до $220 \mathrm{~km}$ является сильноиндуктивным, и вдоль него поле распространяется только в виде ПЭВ. Продолжая ПЭВ к излучателю (приводной радиостанции), получаем сплошную линию на рис. 1. Отличие от измеренных значений поля от излучателя до $70 \mathrm{~km}$ показывает, что на этом участке к ПЭВ вносится добавка в виде еще одного поля. Чтобы выяснить зависимость этого нового поля от расстояния, отнимем измеренные значения поля от вычисленного по формуле (1). Значения нового поля показаны ромбиками в билогарифмическом масштабе на рис. 3. Полученные ромбики удовлетворительно ложатся на прямую сплошную линию рис. 3, которая получается линейной аппроксимацией [11]. Результат означает, что добавочное новое поле описывается следующим степенным законом:

$$
E(R)=\left|E_{z}(\mathrm{mV} / \mathrm{m})\right|=\frac{110}{R^{1.5}(\mathrm{~km})} .
$$

Полное измеряемое поле на втором участке будет суммой полей (1) и (6). Числа в (6) установлены с погрешностью менее $\pm 3 \%$.

Насколько известно, функциональная зависимость (6) пока еще теоретически не установлена. Обратим внимание, что такая же пространственная характеристика для электрического поля установлена в работе [16], где представлены результаты измерений уровней вертикальной компоненты электрического поля излучения разрядов молнии. В частности, результат означает, что исследованный регион в [16] не имеет вечной мерзлоты.

\section{Заключение}

Из анализа результатов измерения вертикальной компоненты электрического поля установлено, что на частоте $255 \mathrm{kHz}$ на расстоянии до $70 \mathrm{~km}$ от излучателя имеем участок, где поле с расстоянием $R$ спадает как $1 / R^{1.5}$. Такая функциональная зависимость еще не получила своего теоретического обоснования. На больших расстояниях из-за наличия вечной мерзлоты, лежащей на проводящей породе, поле приобретает характер ПЭВ и спадает с расстоянием как $R^{-0.5} \exp (-B R)$, где $B-$ функция частоты излучающей радиостанции и поверхностного импеданса $\delta$ радиотрассы. Полученный результат означает, что над импедансными структурами существует реальная возможность значительного электродинамического усиления электромагнитного поля на поверхности с сильноиндуктивным поверхностным импедансом (относительно бесконечно проводящей плоскости).

Авторы выражают искреннюю благодарность рецензенту, замечания которого способствовали существенному улучшению настоящей работы.

\section{Список литературы}

[1] Sommerfeld A. // Math. Ann. 317 (1896).

[2] Дацко В.Н., Копылов А.А. // УФН. 2008. Т. 178. № 1. C. $109-110$.

[3] Тиходеев С.Г., Гинниус Н.А. // УФН. 2009. № 179. С. 1003.

[4] Кузелев М.В., Орликовская Н.Г. // ЖЭТФ. 2016. Т. 150. Вып. 6 (12). С. 1252-1261.

[5] Wait J.R. Electromagnetic waves in stratified media. Oxford, Paris: Pergamon Press, 1962.

[6] Макаров Г.И., Новиков В.В. // РЭ. 2000. Т. 45. № 9. C. $1029-1036$.

[7] Цыдыпов Ч.Ц., Цыденов В.Д., Башкуев Ю.Б. Исследование электрических свойств подстилающей среды. Новосибирск: Наука, 1979.

[8] Башкуев Ю.Б., Хаптанов В.Б., Дембелов М.Г. // Письма в ЖТФ. 2010. Т. 36. Вып. 3. С. 88-95.

[9] Электронный ресурс. Режим доступа: http://www.atlasyakutia.ru/weather/map_frozen_earth.html

[10] Башкуев Ю.Б. Электрические свойства слоистых природных сред. Новосибирск: Изд-во СО РАН, 1996.

[11] Тейлор Дж. Введение в теорию ошибок. М.: Мир, 1985. $272 \mathrm{c}$.

[12] Балханов В.К., Башкуев Ю.Б., Ангархаева Л.Х. // ГИАБ. 2015. № 12. С. 281-285. Электронный ресурс. Режим доступа: http://www.giab-online.ru/files/Data/2015/ 12/281_285_12_2015.pdf

[13] Фейнберг Е.Л. Распространение радиоволн вдоль земной поверхности. М.: Физматлит, 1999. 496 с.

[14] Макаров Г.И., Новиков В.В., Рыбачек С.Т. Распространение электромагнитных волн над земной поверхностью. М.: Наука, 1991.

[15] Акиндинов В.В., Нарышкин В.И., Рязанцев А.М. // РЭ. 1976. T. 21. № 5. C. 913-944.

[16] Балханов В.К., Башкуев Ю.Б., Козлов В.И., Муллаяров В.А. // ЖТФ. 2009. Т. 79. Вып. 1. С. 152-155. 